\title{
Investment Sentiment in Finance Market
}

\author{
Han Chen ${ }^{1, \text { a, }, * \dagger}$, Liang Shan ${ }^{2, b, *, \dagger}$, Chenhui Wang ${ }^{3, c, ~ *, \dagger}$ \\ ${ }^{1}$ Science Department, University of Windsor, Windsor, Ontario, Canada \\ ${ }^{2}$ Math Department, University of California, Irvine, Irvine, United States \\ ${ }^{3}$ College of Letters \& Science, University of Wisconsin-Madison, Madison, Wisconsin, United States \\ *Corresponding author.Email: ${ }^{a}$ chen1er@uwindsor.ca, ${ }^{b}$ lshan5@uci.edu, ${ }^{c}$ cwang628@wisc.edu \\ These authors contributed equally.
}

\begin{abstract}
Investment emotions are a huge topic in investment finance. Investment emotions influence the entire investment process, from choices to decisions to returns. However, not everyone has a deep understanding of investment sentiment. This article provides detailed information on how to measure investment sentiment and how it affects financial markets. First, some of the indicators that are already available today are systematically described, for example, Commitment of traders, Volatility index, Moving average, etc. We compare the strengths and weaknesses of each indicator. After that, we illustrate the performance of investment sentiment in different financial markets to demonstrate the impact of investment sentiment on financial markets. We present the application of investment sentiment to big data analytics. Finally, we suggest the need to have a big picture view and not blindly listen to financial news and other advice to avoid emotional investing. We conclude that investment sentiment impacts investors' decisions as well as investment returns.
\end{abstract}

Keywords: Investment Sentiment, Financial Market, Measurement Indexes, Avoid Emotional Investing

\section{INTRODUCTION}

The systematic divergence of investors' expectations about the future is referred to as investment sentiment. Investor mood is a tough topic to quantify, but it represents market participants' desire or expectations to invest. On Wall Street, an ancient saying is that markets are driven by just two forces: fear and greed. There is a trade-off between these two components; if fear exceeds desire, investors become pessimistic, and the stock market collapses. If greed triumphs over fear, investors become optimistic, and the stock market rises. In 1996, Stein presented the concept of investing emotion for the first time. In 2007, Baker and Wurgler connected it to stock market results.

The connection between investing emotion and financial markets will be discussed in this article. We'll look at how investment sentiment is assessed, how it affects financial markets, how it's used in practice, and how it's changing. First, we examine the benefits and drawbacks of different investing attitude indicators. Second, we look at how sentiment affects total stock returns, stock return volume, and stock return volatility in the stock market and the cryptocurrency and commodities markets. Finally, we show how big data and investment sentiment are related nowadays, examine the effect on investment choices, and suggest theoretical methods to prevent emotional investing.

\section{MEASUREMENT OF INVESTMENT SENTIMENT}

\subsection{The Commitment of Traders}

The three main participants are commercial traders (hedgers), non-commercial traders (big speculators), and retail traders (small speculators). Hedgers purchase when the market is at its lowest point, whereas speculators sell when the market is at its highest point. Furthermore, speculators are bullish when the market reaches its peak, whereas hedgers are pessimistic when the market reaches its bottom. As a result, speculators' positioning signals the trend's direction, while commercial positioning may signal a reversal [1].

The following are the strengths of the commitment of traders. The CFTC in the United States compiles and publishes these reports, which show how many long, short, and spread positions make up the open interest. The report may assist traders in deciding whether to 
take short or long positions in their transactions. There are four different COT reports: the Legacy, Supplemental, Disaggregated, and the Traders in Financial Futures [2].

The weaknesses are listed below. The standards for governing a document that is supposed to encourage openness are opaque. Even the disaggregated data is much too skewed to reflect the market correctly.

\subsection{Volatility Index}

The standard deviation of past market values is referred to as volatility in technical terms. Volatility refers to the degree to which a price varies over time, in addition to financial terms. When the CBOE Volatility Index (VIX) gaining confidence in the market.

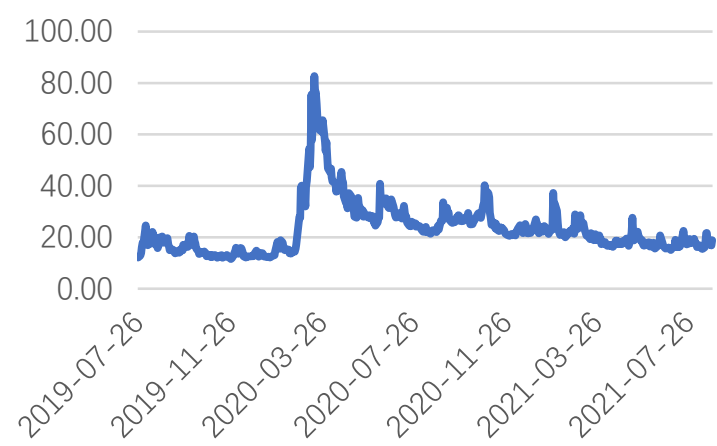

Figure 1. Volatility index from July 2019 to August 2021.

Noted: The horizontal axis represents the period from July 26, 2019, to July 26, 2021, and the vertical axis represents the value of the index.

The strengths of VIX are listed below. The VIX may be beneficial to investors, particularly those looking to safeguard their holdings. Because the VIX has a significant negative connection with the S\&P 500 (Standard \& Poor's 500), this is the case. In addition, the VIX has some short-term forecasting abilities [3].

The following are the weaknesses of the VIX. The daily fluctuations in the VIX tell us what is going on right now and what has occurred in the past, not what will happen in the future. As a result, day-to-day VIX fluctuations have relatively little forecasting power [3].

\subsection{Stocks Above/Below Moving Averages}

There are two types of Moving Average (MA) [4].

Simple Moving Average (SMA)

$$
\mathrm{SMA}=\frac{A 1+A 2+\cdots+A n}{n}
$$

In which $A$ is the Average in period $n, n$ is the number of periods.
Exponential Moving Average (EMA)

$$
E M A_{t}=\left[V t \times\left(\frac{s}{1+d}\right)\right]+E M A_{y} \times\left[1-\left(\frac{s}{1+d}\right)\right]
$$

In which $E M A_{t}$ is EMA today, $\mathrm{V}_{\mathrm{t}}$ is valued today, $E M A_{y}$ was EMA yesterday, $s$ is smoothing, $d$ is the number of days.

The strengths of this measurement are listed below [5]. It is straightforward to use. It may be tailored to any period and is ideal for both long-term and short-term traders - moving averages aid in the decomposition of price charts. To obtain a rudimentary sense of the price movement, look at the direction of the moving averages. It has been documented that it can be used to predict stock returns [6].

The following are the weaknesses [5]. First, the only historical price information is used to calculate moving averages. Chart indicators, like any other kind of technical analysis tool, ignore changes in fundamental variables that may influence a security's future performance, such as new rivals, more significant or lower demand for goods in the sector, and changes in the company's management structure. Furthermore, in principle, a moving average should show a continuous increase in the price of a security over time. Second, there are no universal rules applicable to all markets since each asset has its unique price history and volatility levels. Finally, moving averages don't necessarily represent a cyclical pattern of stock activity. If a market is jumping around a lot, moving averages are unlikely to detect any major trends.

\subsection{Fear and Greed Index}

The CNN fear and greed index looks at seven distinct variables to determine how much fear and greed are present in the market [7].

The strengths are listed below. The fear and greed index has historically been a good predictor of a market shift. It's a forward-looking measure of expected stock market volatility that market participants compute using observed option prices [8].

The following is the weakness of this index. The ideal approach to invest in stocks is to purchase and hold, and instruments like the Fear and Greed Index may push investors to buy and sell equities often. Unfortunately, this method yields less favourable results [8].

\subsection{Comparison of the Indicators}

The comparisons of the indicators are listed in Table 1. We compare the accuracy of data sources, the accuracy of reflection of the market, transparency of data measurement, and market predictability. 
Table 1. Comparison of the indicators

\begin{tabular}{|c|c|c|c|c|}
\hline $\begin{array}{l}\text { Evaluation } \\
\text { Indicators } \\
\end{array}$ & $\begin{array}{l}\text { Accuracy of } \\
\text { data sources }\end{array}$ & $\begin{array}{c}\text { Accuracy of reflection of the } \\
\text { market }\end{array}$ & $\begin{array}{l}\text { Transparency of } \\
\text { data measurement }\end{array}$ & Market predictability \\
\hline $\begin{array}{l}\text { The } \\
\text { commitment } \\
\text { of Traders }\end{array}$ & $\begin{array}{l}\text { Compiled and } \\
\text { published by the } \\
\text { CFTC. }\end{array}$ & $\begin{array}{l}\text { Massive deviations, which do } \\
\text { not correctly reflect the } \\
\text { market. }\end{array}$ & $\begin{array}{l}\text { Measurement } \\
\text { criteria are not } \\
\text { transparent and } \\
\text { clear. }\end{array}$ & $\begin{array}{c}\text { Only data available, not } \\
\text { easily linked to market } \\
\text { forecasts. }\end{array}$ \\
\hline $\begin{array}{l}\text { Volatility } \\
\text { Index }\end{array}$ & $\begin{array}{l}\text { Created by } \\
\text { CBOE and } \\
\text { maintained by } \\
\text { CBOE Global } \\
\text { Markets. }\end{array}$ & $\begin{array}{l}\text { Very accurate in informing } \\
\text { investors of what has } \\
\text { happened and what is } \\
\text { happening in the market. }\end{array}$ & $\begin{array}{l}\text { Very clear } \\
\text { measurement } \\
\text { criteria }\end{array}$ & $\begin{array}{c}\text { The VIX has some } \\
\text { short-term forecasting } \\
\text { ability. }\end{array}$ \\
\hline $\begin{array}{l}\text { Stocks } \\
\text { above/below } \\
\text { moving } \\
\text { averages }\end{array}$ & $\begin{array}{l}\text { Statistical data } \\
\text { from investors } \\
\text { themselves. }\end{array}$ & $\begin{array}{c}\text { It only reflects past stock } \\
\text { price changes and } \\
\text { sometimes does not always } \\
\text { capture any significant } \\
\text { patterns. }\end{array}$ & $\begin{array}{l}\text { It depends on the } \\
\text { investor itself }\end{array}$ & $\begin{array}{c}\text { There are no universal } \\
\text { principles that can be } \\
\text { applied to all markets; a } \\
\text { basic sense of price } \\
\text { movement can be } \\
\text { obtained and may be } \\
\text { used to predict stock } \\
\text { returns. }\end{array}$ \\
\hline $\begin{array}{l}\text { Fear and } \\
\text { Greed Index }\end{array}$ & $\begin{array}{l}\text { Developed by } \\
\text { CNNMoney. }\end{array}$ & $\begin{array}{l}\text { Provides only theoretical } \\
\text { market responses, in other } \\
\text { words, for information only }\end{array}$ & $\begin{array}{l}\text { Very clear } \\
\text { measurement } \\
\text { criteria. }\end{array}$ & $\begin{array}{l}\text { It is a forward-looking } \\
\text { indicator of anticipated } \\
\text { stock market volatility. }\end{array}$ \\
\hline
\end{tabular}

\section{IMPACT OF INVESTMENT SENTIMENT ON FINANCIAL MARKET}

This section reviews the literature examining the effects of investor sentiment on different financial markets, including the stock market, cryptocurrency market, commodity market, and investment sentiment in financial markets during the Covid-19 pandemic.

\subsection{Investment Sentiment and Stock Market}

A significant amount of research has demonstrated the great influence of investor sentiment on the stock market. This is important because investment sentiment plays a critical role in helping investors make investment decisions in the stock market. And we review this stream of literature below.

\subsubsection{Investment Sentiment and Overall Stock Returns}

Studies have indicated that investment sentiment, including online investment, can affect and predict stock returns [9]. Specifically, investor fear plays an important role in stock returns [10]. Besides, different types of investor sentiment have different effects on stock returns. Optimistic investment sentiment will lead to higher stock returns within the month, while pessimistic investor sentiment will decrease the stock returns [11].

Although investor sentiment is closely related to stock returns, there is variation in the effect of investment sentiment due to different factors. One factor is the type of firm. The impact of investor sentiment on stock returns is greater when the firms are not easy to arbitrage or are valued $[9,10,12]$. This is because the mispricing of stocks caused by investor sentiment is not immediately corrected for firms that are difficult to arbitrage [13]. What's more, the existence of a financial crisis would lead to a greater impact of investor sentiment on stock returns $[10,12]$.

\subsubsection{Investment Sentiment and Stock Return Volatility}

Investment sentiment plays a critical role in influencing and predicting stock return volatility. And studies have demonstrated the importance of the shifts in investment sentiment [14]. Positive changes in investor sentiment have a greater impact and can increase stock volatility [14]. Meanwhile, time and stock size are two factors that researchers need to consider when studying the relationship between investor sentiment and stock return volatility. Investors' emotions have a larger impact on stock volatility when the stock size is small and the period is short [15].

What's more, the spillover effect is an important characteristic of the effect of investor sentiment. This means that in addition to self-return volatility, investor sentiment would also cause changes in the volatility of other stocks in the stock market [16]. Hence, the influence of investor's emotions would become more prominent due to the spillover effect. In addition, the study has specified that wood processing products and chemical products industries are two industries that are 
most susceptible to the spillover effect [16]. Therefore, investors' emotions are very likely to have a more significant impact on these industries.

\subsubsection{Investment Sentiment and Stock Trade Volume}

Stock market trade volume is subject to the impact of investment sentiment. For example, bullish investment sentiment may cause investors to become more overconfident, leading to more trades in the stock market [17]. What's more, there is a relationship between investor sentiment and variability of the stock trade volume. By using the Volatility Index as a measurement of investment sentiment, research has found more variability in stock trade volume when there is a greater increase in investment sentiment [18]. In addition, online information is a useful resource to study the relationship between investor sentiment and stock trade volume. The intensity of online ticker searches can reflect investment sentiment and predict trade volume in the stock market [19].

However, the effect of investment sentiment on stock trade volume is not consistent in terms of time. Investor sentiment has a larger impact on trade volume in the short run, and the influence gradually decreases over time [20]. What's more, the influence of investor sentiment differs depending on the investor type. For example, compared with domestic investors, foreign investors are less sensitive to the sentiment, and the influence of investment sentiment on their trading behaviour is smaller and decreases more quickly [20].

\subsubsection{Investment Sentiment in Stock Market during the Covid-19 Pandemic}

During the Covid-19 pandemic, investment sentiment has changed significantly. Information related to COVID-19 has led to a big increase in investor sentiment by using the VIX index [21]. Besides, people can easily find a lot of information related to the Covid19 pandemic on the Internet. And investors would become more fearful about the pandemic by searching related information online [22]. Overall, investor sentiment has become more pessimistic and negative during the global pandemic.

And the pandemic-induced negative investment sentiment would affect the stock market negatively and significantly. One major impact is that it would reduce the overall stock returns. During the pandemic, investors pay more attention to their health rather than their wealth, and the pessimistic sentiment causes investors to stop investing in the stop market and leads to a decrease in future stock returns [23]. However, not all stock returns have suffered from the negative investor emotions caused by the Covid-19 pandemic. For example, during the pandemic, people's needs for medical care have increased. Besides, people have to work remotely, and their needs for digital devices and software have also increased. Hence, the stock returns of the pharmacy and digitalization industry have increased during the pandemic [24]. Meanwhile, research has found that after the onset of the Covid-19 pandemic, worries and fear have led to more fluctuations and significant changes in trade volume in the stock market [25].

\subsection{Investment Sentiment and Cryptocurrency Market}

The cryptocurrency market is susceptible to investor sentiment. There is a relationship between investor sentiment and returns of different types of cryptocurrencies. For example, investor sentiment on Twitter is useful in predicting returns of major cryptocurrencies, including Bitcoin, Bitcoin Cash, Litecoin, Ethereum, Ripple, Monero, and Dash [26, 27]. However, there are some differences between the effects of optimistic and pessimistic investment sentiment. Investor sentiment of optimism has a stronger and more enduring impact on cryptocurrencies returns than investment sentiment of fear [28].

In addition, investment sentiment can influence the volatility and trading volume of cryptocurrencies [29]. And investors' expectation about stock market has a specific impact on the cryptocurrency market. Optimistic investor sentiment about the stock market can lead to a more stable trading volume of major cryptocurrencies and less volatility in the cryptocurrency market [30].

\subsection{Investment Sentiment and Commodity Market}

Investment sentiment can influence the commodity market. One aspect is that it would change investors' demand for relevant information. Stronger investor sentiment would lead investors to search for more information about the commodities [31]. Another aspect is that investors' emotions would affect commodity returns. Both optimistic and fearful investor emotions significantly impact returns of different commodities futures related to metals, agriculture, livestock and energy [32]. However, their influences are different. Pessimistic investment sentiment generates a higher return average in terms of commodity futures [32]. What's more, the effect of investor sentiment on commodity returns is influenced by some other factors. Commodity futures with higher volatilities are more likely to be influenced by investor sentiment [32]. Besides, investor types would also impact the effect of investor sentiment. When money managers change their sentiment positively, volatilities of the commodity 
futures are reduced, and higher commodity returns can be generated; however, positive change of producer and user investment sentiment would have an opposite effect [33].

\subsection{Summary of the Impact of Investment Sentiment on Financial Market}

The impact of investment sentiment can be seen in various financial markets, including the stock market, cryptocurrency market, and commodity market. Investors' emotions are associated with changes in returns, volatilities, and trade volumes in different financial markets. However, it is important to notice that the effect of investor sentiment varies in all these three markets. The impact of investment sentiment would be influenced by a couple of different factors, such as sentiment type, firm or industry type, investor type, and time duration. What's more, it is also crucial for us to understand how investment sentiment changes and influences the stock market before and after the Covid-19 pandemic. The pandemic-related negative sentiment has led to fewer stock returns, more volatility and changes in trade volume.

\section{FUTURE TRENDS IN INVESTMENT SENTIMENT}

This section will discuss the practical application of investment sentiment and how to avoid emotional investing.

\subsection{Application of Investment Sentiment}

Research has shown that investor sentiment has many practical applications and makes an excellent contribution to the study of financial markets.

\subsubsection{Big Data and Investment Sentiment}

Big data is critical for businesses that need to collect large amounts of data, such as social networks, and one of the most significant advantages of deep learning is the ability to analyze large amounts of data. Deep understanding has the potential to extract incredible pieces of information from massive amounts of data. These social networks can be observed in today's stock market. Studies have shown that people in financial and social networks can correctly predict the stock market. We can extract their sentiments about stocks from the authors' words to predict future market movements [34]. According to studies, the dominant daily mood in financial news has impacted stock market sales and purchases. If financial news is gathered and analysed as part of an investing strategy, it may lead to short- and long-term profits [35]. In summary, the use of big data to analyze investment sentiment can impact market direction. The study of investment sentiment based on big data will give investors some guidance.

\subsubsection{Investment Decisions and Investment Sentiment}

Strengthening investor sentiment research, as well as comprehending and grasping the process and changing features of its creation, may help individuals get a more profound knowledge of the capital market's operating rules and offer practical assistance for investment choices. Research shows that heuristics and biases prevail in investors when they make investment decisions [36]. This shows that investment emotions play a role in individual investment decisions. Another study shows that market sentiment could be valuable in driving firms' investment decisions [37]. In summary, investment sentiment affects investment decisions for both companies and individuals.

\subsection{How to Avoid Emotional Investing}

When asset values are constantly changing, it's hard not to be swayed by the emotional part of life. When the stock market drops and asset values fall, there may be concern about the impact on the overall financial picture. When the market turns around and starts to rise, one may feel overconfident and ready to take more risks to see the assets grow even more. Therefore, we will talk about ways to prevent emotional investing.

\subsubsection{Big Picture Perspective}

Studies have shown that investors' emotions can affect returns [38]. To prevent investing emotionally in yourself, it is necessary first to have a big picture view. Starting an investment has a purpose, which influences how the portfolio is placed. When the market becomes more volatile, review those goals and see if anything has changed. Try asking yourself one question. If the only thing that has changed is the short-term value of the portfolio, should the long-term strategy be affected. These big-picture inquiries may help focus on something other than the immediate pain.

\subsubsection{Turn Off The Headlines of Financial News}

Spectacular headlines appear to be everywhere during times of market turbulence. If not handled with care, anxiety and emotional responses are more probable. Unfortunately, no forecaster can accurately anticipate the market's path in the near future, and no forecaster is aware of someone else's particular circumstances. According to studies, investors pay the same amount of attention to positive and negative stock market news. On the other hand, investors' attentiveness to good news depends on their understanding of the specific stock market [37]. When investors have a better 
understanding of equities, they are less likely to trust financial headlines. Rather of watching from the sidelines, they investigate what is causing the upheaval.

\subsubsection{Stop Double-Checking Your Assets on Daily Basis}

Applying a long-term perspective and looking less at assets is one way to minimize the emotional impact of market volatility. Emotional psychologists believe that investors' emotions affect their risk assessment and the value of the currencies they invest in $[39,40]$. When all you hear is terrible market performance, increasing the frequency of checking assets only increases concern. By not monitoring portfolio balances on a daily basis, the chances of sticking with it and reaping the long-term benefits of the strategy can be improved.

\subsubsection{Diversify Your Portfolio}

When only one stock is held, a change in the market will put the individual investor in a dangerous position. This change may directly cause the investor to abandon this stock and focus his investment on the following stock that he considers favourable. This interplay creates a vicious circle. Diversification can be an excellent way to avoid this situation.

\section{CONCLUSION}

It is unlikely to be disputed that investor sentiment is an essential component of economic activity. In this article, we provide an overview of how investment sentiment affects financial markets. The literature argues that it is a form of uncertainty that affects investors' subjective assessments of future returns and thus their investment decisions and that these factors, when combined, can have a significant impact on markets. We have analyzed the effects of investment sentiment on stock markets, commodity markets and virtual currency markets and found that it partially affects the volatility of returns and trading volume. The impact of investor sentiment is different in each of the three markets. The effect of investment sentiment can be influenced by many other factors, such as type of sentiment, type of company or industry, type of investor and length of time. In addition, we provide some specific solutions on how to avoid emotional investing. Although we have listed some measures of investment sentiment here, the measurement of sentiment is difficult. We have not mentioned other measures in society here, and more novel criteria could be systematically introduced.

Future suggestions include the relationship between data on investment sentiment and stock market returns, investment sentiment and virtual currency market stability, and the relationship between investment sentiment and the percentage influence of decisionmakers on investment decisions.

\section{REFERENCES}

[1] Babypips.com, Understanding the COT report. Obtained from: https://www.babypips.com/learn/forex/understandi ng-cot-report

[2] Hayes, A., Commitments of traders report (COT), 2021. Obtained from:

https://www.investopedia.com/terms/c/cot.asp

[3] Hait, D., The pros and cons of VIX, the Market's Fear Gauge, 2017. Obtained from: https://www.barrons.com/articles/the-pros-andcons-of-vix-the-markets-fear-gauge-1505942074

[4] Fernando, J., Moving average (MA), 2021. Obtained from: http://www.investopedia.com/terms/m/movingaver age.asp

[5] Maverick, J., Advantages and disadvantages of the simple moving average (SMA)?, 2020. Obtained from:

https://www.investopedia.com/ask/answers/013015 /what-are-main-advantages-and-disadvantagesusing-simple-moving-average-sma.asp

[6] Ma, Y., Yang, B.,Su, Y., Stock return predictability: Evidence from moving averages of trading volume, Pacific-Basin Finance Journal, 2021, vol.65, $101494 . \quad$ DOI: https://doi.org/10.1016/j.pacfin.2021.101494

[7] Liberto, D., Fear and Greed Index, 2021. Obtained from: https://www.investopedia.com/terms/f/fearand-greed-index.asp

[8] Shaikh, I., Padhi, P., The implied volatility index: Is 'investor fear gauge' or 'forward-looking'? Borsa Istanbul Review, 2015, vol. 15, pp. 44-52. DOI: http://dx.doi.org/10.1016/j.bir.2014.10.001

[9] Seok, S., Cho, H., Ryu, D., Firm-specific investor sentiment and daily stock returns, The North American Journal of Economics and Finance, 2019, vol. $\quad 50, \quad 100857 . \quad$ DOI: https://doi.org/10.1016/j.najef.2018.10.005

[10] Smales, L., The importance of fear: Investor sentiment and stock market returns, Applied Economics, 2017, vol. 49, pp. 3395-3421. DOI: https://doi.org/10.1080/00036846.2016.1259754

[11] Fang, H., Chung, C., Lu, Y., et al., The impacts of investors' sentiments on stock returns using fintech approaches. International Review of Financial 
Analysis, 2021, vol. 77, 101858. DOI: https://doi.org/10.1016/j.irfa.2021.101858

[12] Kadilli, A., Predictability of stock returns of financial companies and the role of investor sentiment: A multi-country analysis, Journal of Financial Stability, vol. 21, pp. 26-45. DOI: https://doi.org/10.1016/j.jfs.2015.09.004

[13] Seok, I., Cho, H., Ryu, D., Stock market's responses to intraday investor sentiment. The North American Journal of Economics and Finance, 2021, vol. 58, 101516. DOI: https://doi.org/10.1016/j.najef.2021.101516

[14] Qiang, Z., Shu-e, Y., Noise trading, investor sentiment volatility, and stock returns, Systems Engineering-Theory \& Practice, 2009, vol. 29, pp. 40-47. DOI: https://doi.org/10.1016/S18748651(10)60010-5

[15] Maitra, D., Dash, S., Sentiment and stock market volatility revisited: A time-frequency domain approach, Journal of Behavioral and Experimental Finance, 2017, vol. 15, pp. 74-91. DOI: https://doi.org/10.1016/j.jbef.2017.07.009

[16] Jiang, S., Jin, X., Effects of investor sentiment on stock return volatility: A spatio-temporal dynamic panel model, Economic Modelling, 2021, vol. 97, pp. 298-306. DOI: https://doi.org/10.1016/j.econmod.2020.04.002

[17] Liu, S., Investor sentiment and stock market liquidity, Journal of Behavioral Finance, 2015, vol. 16, pp. 51-67. DOI: https://doi.org/10.1080/15427560.2015.1000334

[18] Lei, V., So, S., Invesor sentiment and trading volume, SSRN Working Paper, 2011, 2007696. DOI: http://dx.doi.org/10.2139/ssrn.2007696

[19] Joseph, K., Wintoki, M., Zhang, Z., Forecasting abnormal stock returns and trading volume using investor sentiment: Evidence from online search, International Journal of Forecasting, 2011, vol. 27, pp. 1116-1127. DOI: https://doi.org/10.1016/j.ijforecast.2010.11.001

[20] Kim, K., Ryu, D., Term structure of sentiment effect on investor trading behaviour, Finance Research Letters, 2021, forthcoming. DOI: https://doi.org/10.1016/j.frl.2021.102005

[21] John, K., Li, J., COVID-19, volatility dynamics, and sentiment trading, Journal of Banking \& Finance, 2021, forthcoming. DOI: https://doi.org/10.1016/j.jbankfin.2021.106162

[22] Su, Z., Liu, P., Fang, T., Pandemic-induced fear and stock market returns: Evidence from China,
Global Finance Journal, 2021, forthcoming. DOI: https://doi.org/10.1016/j.gfj.2021.100644

[23] Sobia, N., Muhammad, M., Wang, H., et al., The investor psychology and stock market behavior during the initial era of COVID-19: a study of China, Japan, and the United States, Frontiers in Psychology, 2021, vol. 12, pp. 16 DOI: https://doi.org/10.3389/fpsyg.2021.626934

[24] Sun, Y., Wu, M., Zeng, X., et al. The impact of COVID-19 on the Chinese stock market: Sentimental or substantial?, Finance Research Letters, 2021, vol. 38, 101838. DOI: https://doi.org/10.1016/j.frl.2020.101838

[25] Machmuddah, Z, Utomo, S., Suhartono, E., et al., Stock market reaction to COVID-19: Evidence in customer goods sector with the implication for open innovation, Journal of Open Innovation: Technology, Market, and Complexity, 2020, vol. 6, pp. $99 . \quad$ DOI: https://doi.org/10.3390/joitmc6040099

[26] Kraaijeveld, O., De Smedt, J., The predictive power of public Twitter sentiment for forecasting cryptocurrency prices, Journal of International Financial Markets, Institutions and Money, 2020, vol. $\quad 65, \quad 101188 . \quad$ DOI: https://doi.org/10.1016/j.intfin.2020.101188

[27] Naeem, M., Mbarki, I., Suleman M., et al., Does Twitter happiness sentiment predict cryptocurrency?, International Review of Finance, 2020, forthcoming. DOI: https://doi.org/10.1111/irfi.12339

[28] Naeem, M., Mbarki, I., Shahzad, S., Predictive role of online investor sentiment for cryptocurrency market: Evidence from happiness and fears, International Review of Economics \& Finance, 2021, vol. 73, pp. 496-514. DOI: https://doi.org/10.1016/j.iref.2021.01.008

[29] Ahn, Y., Kim, D., Emotional trading in the cryptocurrency market, Finance Research Letters, 2020, forthcoming. DOI: https://doi.org/10.1016/j.frl.2020.101912

[30] Nie, W., Cheng, H., Yen, K., Investor sentiment and the cryptocurrency market. Empirical Economics Letters, 2020, vol. 19, pp. 1253-1262. Obtained from: https://www.researchgate.net/profile/Kuang-ChiehYen/publication/346053756_Investor_Sentiment_a nd_the_Cryptocurrency_Market/links/5fcae458a6f dcc697be035af/Investor-Sentiment-and-theCryptocurrency-Market.pdf 
[31] Aharon, D., Qadan, M., What drives the demand for information in the commodity market? Resources Policy, 2018, vol. 59, pp. 532-543. DOI: https://doi.org/10.1016/j.resourpol.2018.09.013

[32] Zheng, Y., The linkage between aggregate stock market investor sentiment and commodity futures returns, Applied Financial Economics, 2014, vol. 24, pp. 1491-1513. DOI: https://doi.org/10.1080/09603107.2014.925073

[33] Bahloul W., Bouri A., The impact of investor sentiment on returns and conditional volatility in U.S. futures markets, Journal of Multinational Financial Management, 2016, vol. 36, pp. 89-102. DOI: https://doi.org/10.1016/j.mulfin.2016.07.003

[34] Sohangir, S., Wang, D., Pomeranets A., Khoshgoftaar T. M., Big Data: Deep learning for financial sentiment analysis. Journal of Big Data, 2018, vol. 5, pp. 1-25. DOI: https://doi.org/10.1186/s40537-017-0111-6

[35] de Oliveira Carosia, A., Coelho, G., da Silva, A., Investment strategies applied to the Brazilian stock market: A methodology based on sentiment analysis with deep learning, expert systems with applications, 2021, vol. 184, 115470. DOI: https://doi.org/10.1016/j.eswa.2021.115470

[36] Parveen, S., Satti, Z., Subhan, Q., et al., Exploring market overreaction, investors' sentiments and investment decisions in an emerging stock market, Borsa Istanbul Review, 2020, vol. 20, pp. 224-235. DOI: https://doi.org/10.1016/j.bir.2020.02.002

[37]Danso, A., Lartey, T., Amankwah-Amoah, J., et al., Market sentiment and firm investment decisionmaking, International Review of Financial Analysis, 2019, vol. 66, 101369. DOI: https://doi.org/10.1016/j.irfa.2019.06.008

[38] Vamossy, D., Investor emotions and earnings announcements, Journal of Behavioral and Experimental Finance, 2021, vol. 30, 100474 . DOI: https://doi.org/10.1016/j.jbef.2021.100474

[39] Lerner, J., Keltner, D., Beyond valence: Toward a model of emotion-specific influences on judgement and choice, Cognition \& Emotion, 2000, vol. 14, pp. 473-493. DOI: https://doi.org/10.1080/026999300402763

[40] Han, S., Lerner, J., Keltner, D., Feelings and consumer decision making: The appraisal tendency framework, Journal of Consumer Psychology, 2007, vol. 17, pp. 158-168. DOI: https://doi.org/10.1016/S1057-7408(07)70027-X 